\title{
Intraabdominal Roux-en-Y reconstruction
}

\author{
VIROJ WiWANITKIT \\ Wiwanitkit House, Bangkhae, Bangkok 10160, Thailand
}

\section{To the Editor:}

I read the report by Noshiro et al. [1] on intraabdominal Roux-en-Y reconstruction with great interest. Indeed, there are some recent reports on new surgical techniques for Roux-Y reconstruction after laparoscopic distal gastrectomy and these reports have usually mentioned good outcomes $[2,3]$. In regard to the work by Noshiro et al. [1], these authors reached the conclusion that their new proposed intraabdominal Roux-en-Y reconstruction with a novel stapling technique after laparoscopic distal gastrectomy was an acceptable procedure. However, there are some concerns about the new procedure. First, the costs of this operative approach compared to those of the classical approach were not presented, and these data should be provided to help select the option for surgery. Second, although there is some information on the operative and postoperative status of the patients, this information is not complete.
Details of the intraoperative anesthesia regimen and more details of the surgery should be presented. Also, the long-term postoperative outcome should be noted. Third, the small number of subjects, six cases, limits the generalizability of this work.

\section{References}

1. Noshiro H, Ohuchida K, Kawamoto M, Ishikawa M, Uchiyama A, Shimizu S, et al. Intraabdominal Roux-en-Y reconstruction with a novel stapling technique after laparoscopic distal gastrectomy. Gastric Cancer 2009;12:164-9.

2. Takaori K, Nomura E, Mabuchi H, Lee SW, Agui T, Miyamoto Y, et al. A secure technique of intracorporeal Roux-Y reconstruction after laparoscopic distal gastrectomy. Am J Surg 2005;189:17883.

3. Kojima K, Yamada H, Inokuchi M, Kawano T, Sugihara K. A comparison of Roux-en-Y and Billroth-I reconstruction after laparoscopy-assisted distal gastrectomy. Ann Surg 2008;247:962-7.

Offprint requests to: $\mathrm{V}$. Wiwanitkit 